\title{
Proposal for a method of measurement and control of surface quality in the course of abrasive waterjet cutting of material
}

\author{
Ján Kmec ${ }^{1, *}$, Marta Harničárová ${ }^{1,2}$, Cristina Borzan $^{3}$, Marian Borzan ${ }^{3}$, Jan Valíček $^{1,2}$, Jiři \\ Kř́ž ${ }^{4}$, and Milena Kušnerová ${ }^{1}$ \\ ${ }^{1}$ Institute of Technology and Business in České Budějovice, Faculty of Technology, Department of \\ Mechanical Engineering, Okružní 10, 37001 České Budějovice, Czech Republic \\ ${ }^{2}$ Slovak University of Agriculture in Nitra, Technical Faculty, Tr. A. Hlinku 2, Nitra, 949 76, \\ Slovakia \\ ${ }^{3}$ Technical University of Cluj-Napoca, Faculty of Mechanical Engineering, Department of \\ Manufacturing Engineering, 400641 B-dul Muncii, no. 103-105, Cluj-Napoca, Romania \\ ${ }^{4}$ University of Technology, Faculty of Business and Management, Institute of Informatics, Kolejní \\ 2906/4, 61200 Brno, Czech Republic
}

\begin{abstract}
The paper deals with the automation of the hydroabrasive production process, which leads to higher productivity and production optimization. In the submitted work, the basis of control design is a topography function of surface roughness of abrasive waterjet cut walls, and its functional relations to the controlled speed and to the measured mean values of sound pressure level, including a design of a suitable diagram of connections of controlling elements and equipment. The controlled parameter is the final roughness of a cut wall; in the design, the roughness is program-regulated according to the continuously measured root mean square of sound pressure level by means of continuous control of the traverse speed of cutting head.
\end{abstract}

\section{Introduction}

At present, requirements for the performance and ecological factors of machining highstrength and high-hardness materials continuously grow. Usual machining methods are not always suitable from a technical and economical point of view for machining such materials (often marked as difficult to machine); therefore, new, so-called "nonconventional" machining methods have come to be used more broadly. These nonconventional machining methods are applied especially where the classical methods are ineffective or fail completely. They utilize various physical principles of how to machine a material (e.g. chemical, electrical and chemical, mechanical, optical and others). One of these non-conventional methods is the abrasive waterjet cutting of materials or high-speed liquid jet machining, especially machining using a high-speed liquid jet with an admixture of abrasive materials (AWJ-Abrasive WaterJet). The high speed of an outflowing water

* Corresponding author: $\underline{\mathrm{kmec} @ \text { mail.vstecb.cz }}$ 
stream with an admixture of abrasive materials makes it possible to machine intensively, economically and simultaneously ecologically almost all industrial materials ranging from soft to hard materials [1-8]. Thus, this is a highly topical technology just owing to its universality, environmental friendliness and many other properties influencing positively the machining process.

For this technology, many optimization methods were used in practice to cut a material sufficiently. Technologists often set up the cutting parameters empirically. By analysing the current state of the art in the field of the AWJ technology, we found out that the problems of on-line controlling the quality of machined surfaces in production still remain to be unsolved problem $[9,12-13]$. Thanks to the unique capability of the AWJ technology to cut with high accuracy without affecting a material by heat, narrow kerf, or good edge finish without a need of secondary operations, it has gained high popularity also in new industries (aeroplane design and cosmonautics). Potential users clearly considered the strong points of the water jet cutting compared to other processing possibilities.

\section{Proposal for the solution}

As main parameters of the geometry of a cut wall are stated already in previous works the following parameters: surface roughness $R a$, cut trace lag $Y_{\text {ret }}$ (retardation), angle of curvature of cut trace $\delta$ (deviation) and cut depth $h$ [9]. This composition of surface geometric parameters was selected programmatically with regard to their close interconnections in relation to the instantaneous stress-deformation condition of the cut. The selection of these parameters is systematic and newly utilized in analytical procedures. The surfaces generated by classical mechanical technologies exhibit, from the optical point of view, mirror-reflecting surfaces in comparison with the AWJ generated surfaces that are diffusely-reflecting. Surface roughness measurement was made by a commercial optical instrument MicroProf FRT (Fries Research \& Technology $\mathrm{GmbH}$ ) and by a contact profilometer HOMMEL TESTER T8000.

30 samples were prepared using abrasive waterjet cutting technology, with a size of $8 \mathrm{x}$ $20 \times 20 \mathrm{~mm}$ from S235JR (G2), AlMg, ČSN 422712 materials. The experiment was conducted in the company WATING s.r.o. Prešov, Slovakia. The measurement was made within the $8 \mathrm{~mm}$ height of samples, conventionally on 22 levels and 4 sides machined at different traverse speeds of the cutting head $\left(200,150,100\right.$ and $\left.50 \mathrm{~mm} \cdot \mathrm{min}^{-1}\right)$, in 6 different frequency bands (Table 1). In order to study the influence of process factors on sound pressure level, a precision two-axis positioning table was used. Water pressure was generated using a pump Stream Line SL III. As a technological head, a cutting head AutolineTM was deployed.

Table 1. Setting of AWJ input reference technology parameters

\begin{tabular}{|l|c|l|c|}
\hline \multicolumn{1}{|c|}{ Constant factors } & Values & \multicolumn{1}{|c|}{ Constant factors } & Values \\
\hline Pressure $p[\mathrm{MPa}]$ & 300 & $\begin{array}{l}\text { Nozzle-material surface } \\
\text { distance } L[\mathrm{~mm}]\end{array}$ & 2 \\
\hline Orifice diameter $d_{o}[\mathrm{~mm}]$ & 0.25 & Abrasive size [MESH] & 80 \\
\hline Focusing tube diameter $d_{a}[\mathrm{~mm}]$ & 0.8 & Variable factors & Values \\
\hline Focusing tube length $l_{a}[\mathrm{~mm}]$ & 76 & $\begin{array}{l}\text { Traverse speed } v_{p} \\
{\left[\mathrm{~mm} \cdot \mathrm{min}^{-1}\right]}\end{array}$ & $\begin{array}{c}50,100,150, \\
200\end{array}$ \\
\hline $\begin{array}{l}\text { Abrasive mass flow rate ma } \\
{\left[\mathrm{kg} \cdot \mathrm{min}^{-1}\right]}\end{array}$ & 250 & Abrasive material & Garnet \\
\hline Material thickness $b[\mathrm{~mm}]$ & 8 & Cutting head & Paser III \\
\hline
\end{tabular}




\begin{tabular}{|l|c|l|c|}
\hline \multicolumn{4}{|l|}{ Specifications of device PTV - 37- 60 Pump } \\
\hline Intensifier & $\begin{array}{c}\text { Double } \\
\text { acting }\end{array}$ & Water pressure (max) & $415 \mathrm{MPa}$ \\
\hline Power input & $37 \mathrm{~kW}$ & Water flow rate (max) & $3.681 \cdot \mathrm{min}^{-1}$ \\
\hline
\end{tabular}

During the work of collecting data it was introduced a model of an automated production system. Grouping of comprehensive automated technological workplaces with a central automated control allows creating automated production systems on different technological levels (in a direct correlation of production tasks with the degree of automation of individual manufacturing, handling and technological activities). Model of the automated production system is illustrated in Figure 1. The range of activities and functions of individual subsystems of the automated production system is defined as follows:

- Subsystem of the technological system involves a set of elements (machines, tools or products) which participate in the change of physical-mechanical and geometrical characteristics of the processed object (workpiece).

- Subsystem of inter-operational transport and storage involves means of storage and transport which implement the material flow, workpieces, tools, products, waste etc. into comprehensive automated technological workplaces.

- Subsystem of measurement and control concerns monitoring and signalling of technological and handling operations; i.e. measuring the accuracy of particular characteristics of the workpiece, position of production and auxiliary facilities.

Subsystem of sources and energy distribution refers to a set of sources, distributions and regulation elements ranging from central sources to local inputs of individual devices.

- Subsystem of control deals with a set of elements which secure controlling of technological, handling and manufacturing process in the automated production system and integrate other subsystems.

- Subsystem of operative handling involves a set of technological devices providing operative handling in comprehensive automated technological workplaces with objects of technological processing and tools. It includes industrial robots, handling devices and other auxiliary handling tools [10 - 11].

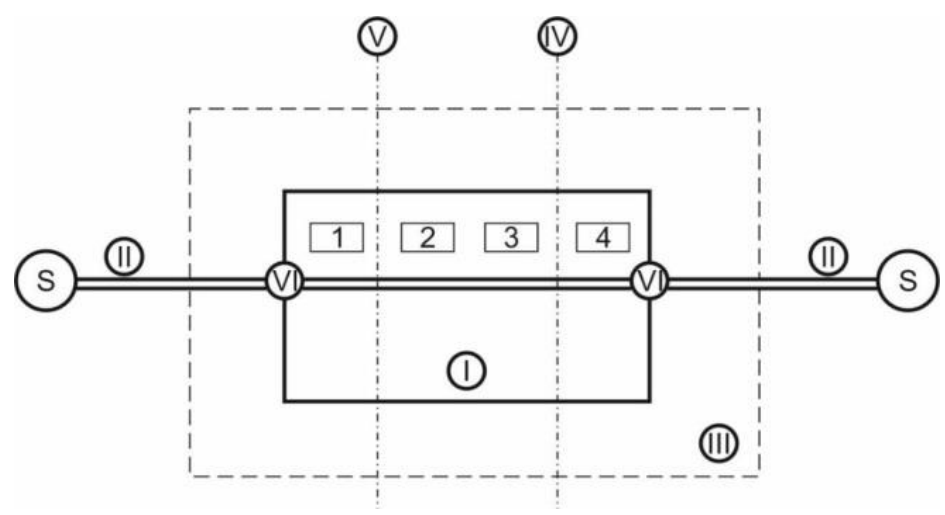

Fig. 1. Model of an automated production system: I - technological system, II - transport and storage, III - measurement and monitoring, IV - energy sources and distribution, V - controlling, VI operative handling 1 - machine, 2 - tool, 3 - product, 4 - material, $\mathrm{S}$ - storehouse 


\section{Measurement of sound pressure level}

In the experimental evaluation of acoustic load, a method of planned experiments was employed (Figure 2).
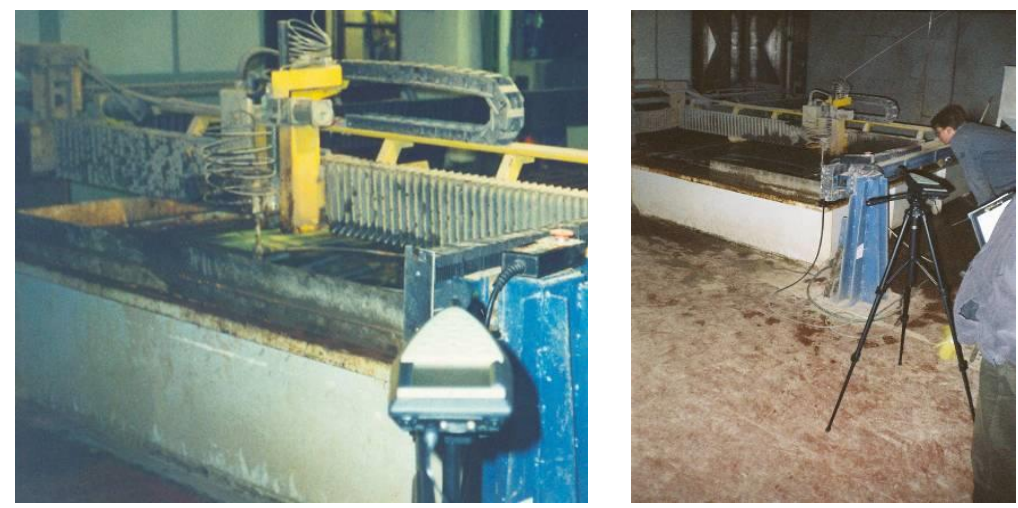

Fig. 2. Measurement of noise of background and surroundings in the company Wating.

To analyse the influence of process factors on the noise level produced by AWJ, these parameters were selected : a ratio of diameters of water orifice and focusing tube $d_{o} / d_{a}$, abrasive mass flow rate $m_{a}$, liquid pressure $p$, and traverse speed of cutting head $v_{p}$.

From mathematical point of view, this can be written as follows (1), where $L_{\text {aeqc }}$ is the overall value of the measured sound pressure. $L_{a e q}$ is calculated by (2), where the parameter $L_{\text {aeqp }}$ is the sound background during operation.

$$
\begin{gathered}
L_{\text {aeqc }}=f\left(v_{p}, p, m_{a}, d_{o} / d_{a}, \ldots\right) \\
L_{\text {aeq }}=L_{\text {aeqc }}-L_{\text {aeqp }}
\end{gathered}
$$

The experiments were carried out in $2^{4}$, i.e. in 16 different relations, so it was able to derive the main correlation relations of the parameter $L_{a e q}$. The regression equation is given as (3)

$$
\log L_{a e q}=b_{0} \log x_{0}+b_{1} \log x_{1}+b_{2} \log x_{2}+b_{3} \log x_{3}+b_{4} \log x_{4}
$$

where $L_{a e q}$ is the sound pressure level as a dependent variable, $x_{0}, x_{1}, x_{2}, x_{3}, x_{4}$ are independent variables and $b_{0}=78.6 ; b_{1}=1.4 ; b_{2}=0.26 ; b_{3}=0.3 ; b_{4}=0.18$ are regression coefficients.

On the basis of analysis of data acquired on samples relation (4) for the optimum sound pressure level that corresponds to a value obtained on the neutral plane was received, where $L_{a e q j}$ is the unit sound pressure level [dB].

$$
L_{\text {aeqopto }}=L_{\text {aeq }} 10^{\log }\left(\frac{10^{2.095}\left(\frac{d_{v}}{d_{a}}\right)^{0.270} m_{a}^{0.002} p^{0.024}}{v_{\text {popt }}^{0.002}}\right)
$$


For the derivation of a technologically optimum traverse speed of cutting head $v_{\text {popt }}$ the functional relation of the speed to the cuttability of material $K_{\text {cuto }}$ in the form of equation (5) was used, where $k_{v p j}$ is an auxiliary coefficient.

$$
v_{\text {popt }}=k_{v_{p_{j}}} \sqrt{10^{-3} R a_{o} K_{\text {cuto }} E_{m a t}}
$$

$K_{\text {cut }}$ is coefficient of cuttability of material and is derived by (6), by measuring the 3 deformation parameters as described above

$$
K_{c u t}=\frac{R a \cdot h}{Y_{r e t}}
$$

The surface roughness parameter $R a_{d}$ is described by semi-empirical equation (7). This relation describes a real trend shape of the cut (the zone of the first contact of the material and the AWJ tool).

$$
R a_{d}=R a_{j} 10^{\sqrt{(\log h)^{2}+\left(\log \frac{1}{Y_{r e t}}\right)^{2}+R a_{r a d}^{2}}}
$$

The auxiliary topography function is expressed by relation (8), where $R a_{j}$ is unit surface roughness $[\mu \mathrm{m}], R a_{o}$ is surface roughness in the neutral plane of cut.

$$
R a_{\text {rad }}=R a_{j} 10^{\log \left(10^{3} R a_{o} Y_{\text {ret }}^{0.25} \sqrt{E_{\text {mat }}}\right)}
$$

By the technologically optimum traverse speed of cutting head $v_{\text {popt }}$, the controlled surface roughness within the whole length of cut is not ensured in the cut (Figure 3), therefore, the traverse speed of cutting head must be continuously controlled [12-13].

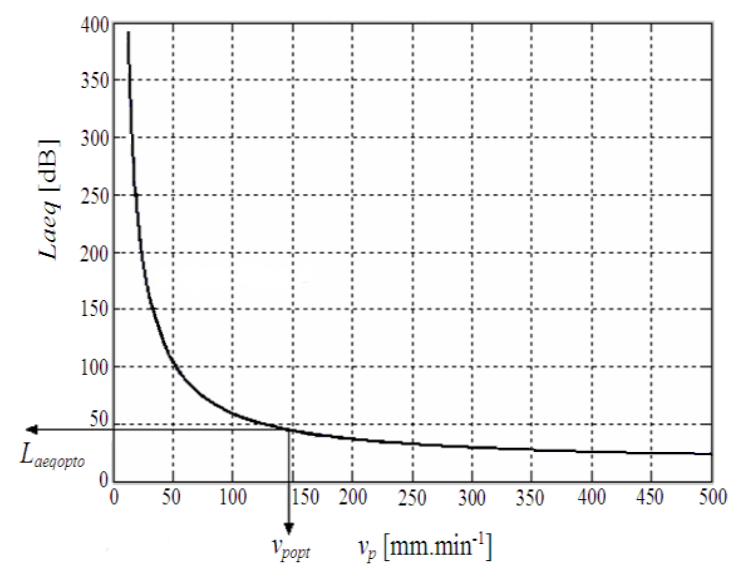

Fig. 3. Dependence of $L_{a e q}$ on traverse speed of cutting head $v_{p}$ for material AISI 304. 


\section{Proposal for method of control loop design}

On the basis of analysis of the concerned problems, a simplified block diagram of control loop is presented in Figure 4.

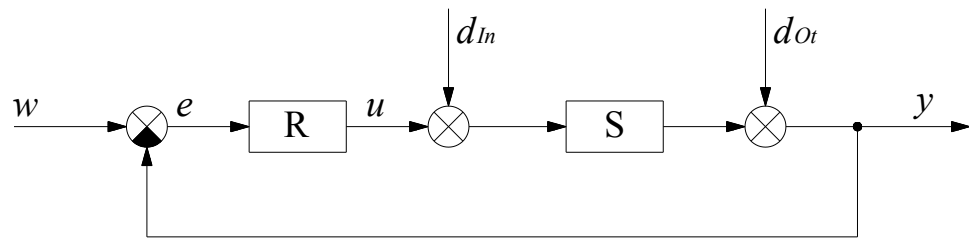

Fig. 4. Simplified block diagram of control loop.

In Figure $4 w$ is the desired value of controlled value $y$, further $e$ is deviation of output value from the desired value $w, R$ controller, $u$ manipulated variable, $d_{I n}$ disturbance at the input, $S$ controlled system, $\mathrm{d}_{\mathrm{Ot}}$ disturbance at the output and $y$ is the output variable. For the illustration of concerned problems of comprehensive design, the simplified model is transformed to the following form (see Figure 5), from which a proposal for the method of controlling the control process follows illustratively [13].

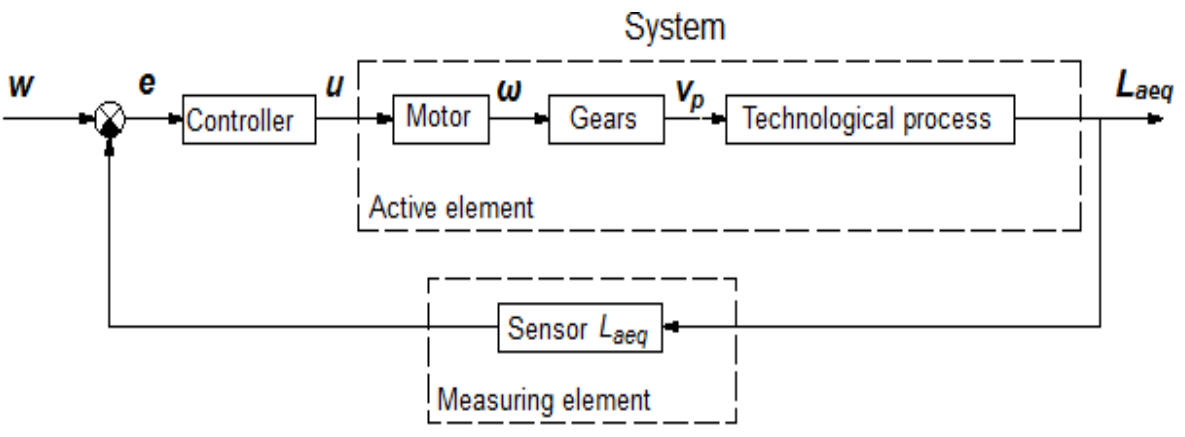

Fig. 5. Block diagram of measurement and control of speed of motion of cutting head $v_{p}$.

In Figure 5, $w$ is the desired value of controlled variable $y ; y=L_{a e q}, L_{a e q}=\mathrm{f}\left(v_{p}\right)$, manipulated variable $u=U$, where $U$ is the voltage input to the electric motor and $\omega$ is the angular velocity of the rotor $\omega=\mathrm{f}(U)$.

\section{Simulation of surface mechanical integrity}

Internal disturbances $d_{I n}$, as well as external disturbances $d_{O t}$ are able to enter the control process (see Figure 4). In general, the term "disturbance" refers to a physical quantity which, without our participation, can affect a quantity being controlled; in our case, it is the preferred sound pressure level $L_{a e q}$. Disturbances are unplanned changes usually acting unpredictably. If they are analysed, they can be expected to enter the control loop at any point (i.e. any element of the controller). However, in engineering practice, we usually take into account only disturbances $d_{O t}$ entering the controlled system $\mathrm{S}$ externally because it is just their impact on the controlled system that is a cause of control implementation. Unless the actual (measured) value of controlled quantity $L_{a e q}$ differs from the desirable quantity, no control process occurs. External disturbances can be, from the point of view of surface 
topography in the process of cutting material, e.g. material inhomogeneities (rather hard grains, cavities, fissures, etc.).

In Simulink environment, disturbances were modelled (Figure 6) behind the system (changes in sound pressure level). When a disturbance occurs (deviation from the preferred value), the designed controller tries to compensate for the controlled quantity so that it may correspond to the preferred value (Figure 7). Figure 7 corresponds to the above-mentioned analytically obtained data, which were confirmed by experimental measurements.

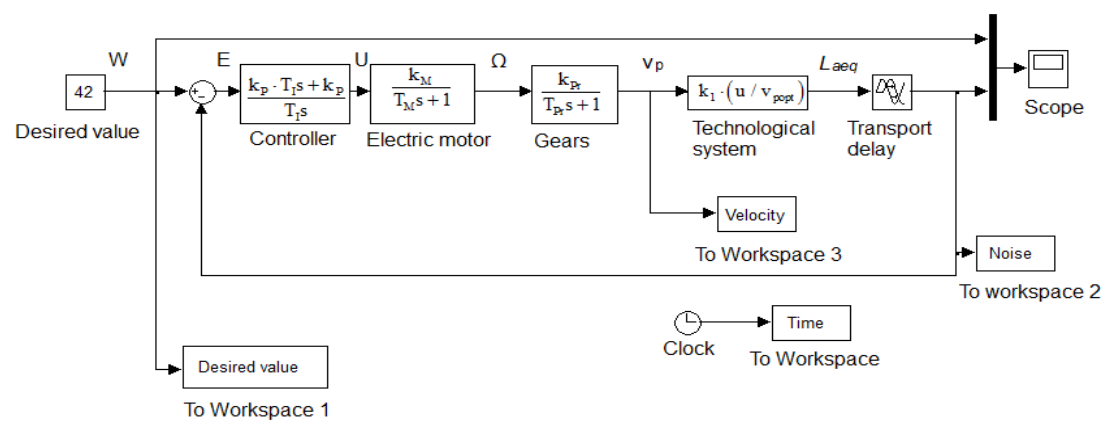

Fig. 6. Diagram of control loop in Simulink environment with modelled disturbances.

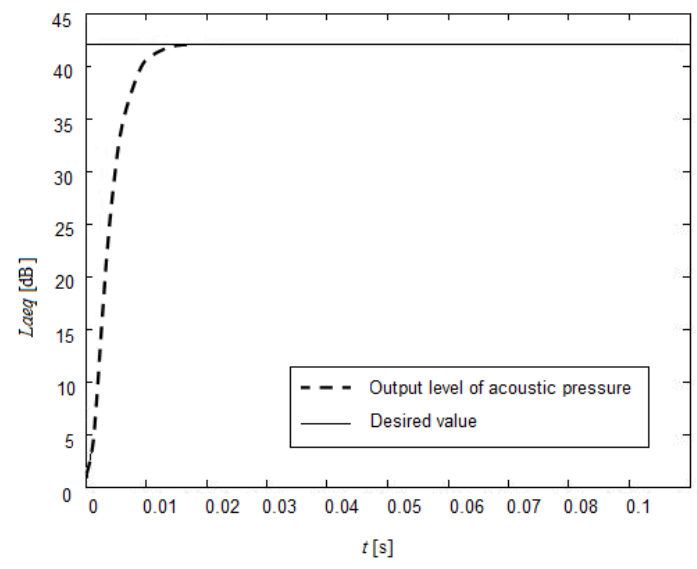

Fig. 7. Control of disturbances due to material cutting using abrasive waterjet.

\section{Conclusions}

The paper aimed to introduce a method of measurement and control of surface quality in the course of abrasive waterjet cutting of material. For the measurement of basic geometric properties of the topography of surfaces newly generated by the AWJ technology, a measuring apparatus was successfully designed, manufactured and tested. The new automated production system was introduced in the WATING Company in Prešov, Slovakia, where all the experiments were performed. The main interpreted geometric parameters $R a, Y_{\text {ret }}$ and $\delta$ were also designed and defined. Results from this stage of solving were used for the elaboration of a proposal for the project of control of quality in the process of cutting. For the instantaneous check of cut condition on a real-time basis, remote measurement of sound pressure level based on an experimentally proved relation of $L_{a e q}$ 
was designed. Also, a control loop with a suitable PI controller was designed, which was verified in Matlab - Simulink environment that fulfil best the practical requirements of technologists. The achieved results can be used in the current needs of Industry 4.0 practice.

This publication was created within the project VEGA, no. 1/0720/18 Research of Alternative Navigation Algorithms for the control of Autonomous Robots in Plant Production and the project SVV201905 granted by Ministry of Education, Youth and Sports of the Czech Republic.

\section{References}

1. A Hace, K. Jezernik, Ieee-Asme T Mech, 9(2004).

2. H. A. G. El-hofy, Advanced machining processes: Nontraditional and hybrid machining processes (New York, McGraw Hill Professional, 2005).

3. M. Gostimirovic, V. Pucovsky, M. Sekulic, D. Rodic, V. Pejic, Int J Adv Manuf Tech 101(2019).

4. A. W Momber, R. Kovacevic, R. Principles of abrasive water jet machining, (Springer Science \& Business Media, 2012).

5. R. T. Deam, E Lemma, D. H. Ahmed, Wear, 257(2004).

6. A. Lebar, M. Junkar, Model. Simul. Mater. Sci. Eng 12, 6 (2004)

7. A. W. Momber, J Mater Process Technol, 83 (1998)

8. M. Hashish, J. Eng. Mater. Technol, 111, 2 (1989)

9. J. Valíček, M. Harničárová, M. Kušnerová, R. Grznárik, J. Zavadil, J. (2013). Meas Sci Rev, 13, 5 (2013)

10. J. Kmec, L. Bičejová, Annals of Faculty of Engineering Hunedoara, 7, 1 (2009)

11. E. Spišák, M. Badida, J. Kmec, L. Sobotová, Acta Mechanica Slovaca, 15, 2 (2011)

12. J. Valíček, S. Hloch, Int J Adv Manuf Tech 48 (2010)

13. J. Valíček, M. Harničárová, M. Kušnerová, H. Tozan, M. Yagimili, A. Király, Characterisation of surface topography for abrasive waterjet technology and its control (Istanbul, Beta, 2014). 